\title{
Getting down to the real question: effects of transfusion triggers on long-term survival and quality of life following septic shock
}

\author{
Martin W. Dünser ${ }^{1 *}$ and James A. Russell ${ }^{2,3}$
}

C 2016 Springer-Verlag Berlin Heidelberg and ESICM

From an intensivist's perspective, the main focus in the management of critically ill patients is survival to intensive care unit discharge. However, from a patient's perspective, the most relevant outcome is to return home in an acceptable functional state. For many years, this discrepancy has largely been ignored. Only through the last decade have we begun to understand the detrimental effects of critical illness on long-term survival and healthrelated quality of life (HQoL) $[1,2]$. Accordingly, only a small number of multicenter randomized controlled trialshave evaluated the effects of therapeutic interventions on long-term outcomes of critical illness (Table 1).

Long-term outcome is particularly poor for patients surviving sepsis or septic shock, with 5-year mortality rates reported as high as $60 \%[3,4]$. Short-term organ dysfunction and the need for artificial life support have been identified as crucial risk factors for unfavorable long-term outcomes in septic shock survivors [5]. Readmissions due to infectious, cardiovascular or pulmonary complications after an episode of sepsis are frequent and occur early following hospital discharge [6]. One possible cause of adverse long-term outcomes of septic shock is prolonged immunomodulation. Sub-clinical inflammation is a well-known risk factor for cardiovascular and all-cause mortality in non-critically ill patients. It has been hypothesized that critical illness induces a state of prolonged sub-clinical inflammation, thus contributing to impaired long-term survival and functional state [7].

\footnotetext{
*Correspondence: Martin.Duenser@i-med.ac.at

${ }^{1}$ Critical Care Department, University College of London Hospital,

235 Euston Road, London NW1 2BU, UK
}

Full author information is available at the end of the article
Accordingly, abdominal sepsis has been found to induce and aggravate atherosclerosis in a murine model [8]. This observation aligns nicely with reports that sepsis survivors continued to exhibit elevated levels of inflammatory markers at hospital discharge [9] and have an increased subsequent risk of cardiovascular events. In addition, proteomics and metabolomics are profoundly altered by sepsis and may contribute to chronic organ dysfunction and impaired outcome.

The Transfusion-Requirements In Septic Shock (TRISS) trial [10] was a well-performed multicenter randomized controlled trial comparing a liberal $(>9 \mathrm{~g} / \mathrm{dL})$ versus a restrictive $(>7 \mathrm{~g} / \mathrm{dL})$ transfusion trigger in 998 septic shock patients. In this issue of the journal, Ryegard and colleagues present the results of a sub-study of the TRISS trial focusing on survival status and HRQoL at 1 year after randomization [11]. Once again, the authors found no between-group differences in any of these variables. In doing so, they could reject $\mathrm{a} \geq 3 \%$ increased risk of death associated with a restrictive transfusion threshold. The study has several strengths including its focus on long-term outcome and the high methodological quality of the underlying trial. On the other hand, the fact that the power analysis for the original trial was based on 90-day and not 1-year mortality [12] must be seen as a limitation of the present sub-study. As suggested by fairly wide confidence intervals, the patient population may have been too small to detect a significant difference in 1 -year survival between study groups. As hemoglobin levels were not documented during the follow-up period, it is furthermore unclear whether different transfusion thresholds also translated into variable recovery patterns from anemia [13]. Chronic anemia could, for example, increase the risk of certain causes of death. Indeed, the authors argue in their discussion that "[...] restrictive

\section{伨




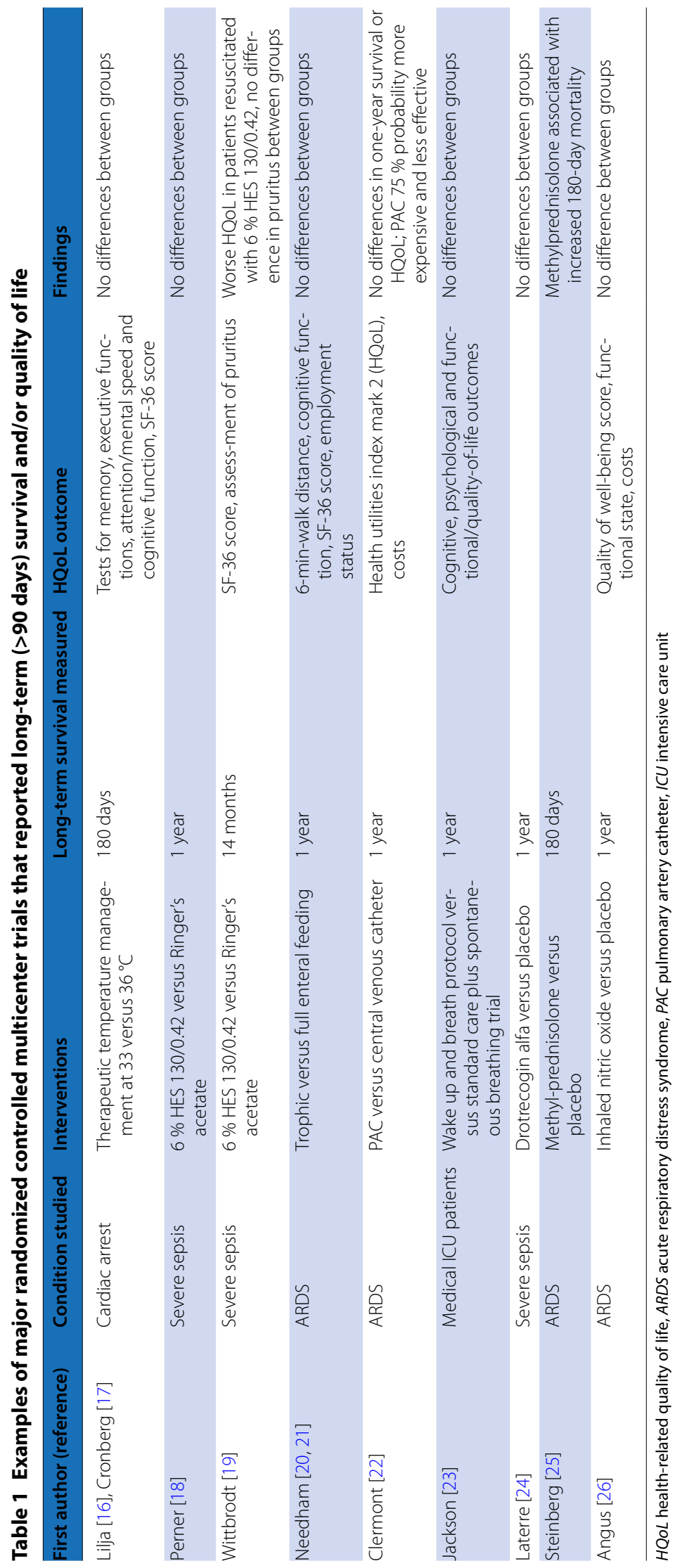


transfusion decreased rates of severe infectious complications in hospitalized patients and increased risk of myocardial infarction in patients with cardiovascular disease" [11]. Unfortunately, the causes of death during the 1-year follow-up period were not evaluated. Finally, while almost full datasets were available to determine 1-year survival status in the whole population, around 25-30\% of data were missing for the nested Danish cohort in which HQoL was determined.

The results of the TRISS trial and its latest sub-study clearly suggest that adoption of a restrictive transfusion policy in patients with septic shock is safe, does not result in relevantly worse short- and long-term outcomes, and spares valuable and short-supplied blood products. Although these results may not be extrapolated to nonseptic critically ill patients, the landmark Transfusion Requirements in Critical Care (TRICC) trial showed equivalence of liberal versus restrictive transfusion triggers in a general intensive care population [14].

What are the implications of these results for future research? Both the TRICC and TRISS trials either excluded or enrolled too few patients particularly vulnerable to anemia, such as those after cardiac surgery, or with acute myocardial ischemia or brain injury [15]. Therefore, future studies still need to elucidate whether application of a restrictive transfusion trigger in critically ill patients with any of these conditions is equally safe. While Ryegard and colleagues could impressively display that the use of a restrictive transfusion threshold does not alter long-term survival and functional outcome of septic shock as compared to a liberal transfusion threshold, this must still be shown for a non-septic critically ill patient population. Given that 'one size fits all' approaches have repeatedly failed to improve the outcome of critically ill patients, future studies should also evaluate whether individual instead of fixed transfusion triggers could improve survival. For general critical care research, we desperately need more observational cohort studies which carefully assess quantitative and qualitative long-term outcomes that allow clinicians and researchers to identify subgroups with increased risks. We further suggest the systematic introduction of long-term survival and HQoL as secondary endpoints in future multicenter trials.

What are optimal long-term outcomes to assess? Is it 1-year survival or HQoL? Evaluation of survival status alone carries the delicate disadvantage that it is a binary variable but does not give any information on HQoL. On the other hand, when using HQoL scores as outcome variables, it is unclear which differences in score results are truly relevant. Other endpoints such as the rate of patients returning home or to their previous place of residency could meaningfully complement long-term outcomes such as those assessed by the TRISS study group. Finally, and most importantly, the ultimate goal of studies in critical care should be to harmonize the intensivists' questions and hypotheses with patient-centered outcomes!

\section{Author details}

${ }^{1}$ Critical Care Department, University College of London Hospital, 235 Euston Road, London NW1 2BU, UK. ${ }^{2}$ Centre for Heart Lung Innovation, St. Paul's Hospital, University of British Colombia, 1081 Burrard Street, Vancouver, BC V6Z 1Y6, Canada. ${ }^{3}$ Division of Critical Care Medicine, St. Paul's Hospital, University of British Colombia, 1081 Burrard Street, Vancouver, BC V6Z 1Y6, Canada.

\section{Compliance with ethical standards}

\section{Conflicts of interest}

None of the authors has a conflict of interest in regards of drugs, techniques or methods discussed in this manuscript. Not related to the manuscript, Dr. Russell reports patents owned by the University of British Columbia (UBC) that are related to PCSK9 inhibitor(s) and sepsis and related to the use of vasopressin in septic shock. Dr. Russell is an inventor on these patents. Dr. Russell is a founder, Director and shareholder in Cyon Therapeutics Inc. (developing a sepsis therapy). Dr. Russell has share options in Leading Biosciences Inc. Dr. Russell is a shareholder in Molecular You Corp. Dr. Russell reports receiving consulting fees from Cubist Pharmaceuticals (now owned by Merck; was formerly Trius Pharmaceuticals; developing antibiotics), Leading Biosciences (developing a sepsis therapeutic), Ferring Pharmaceuticals (manufactures vasopressin and is developing selepressin), Grifols (sells albumin), La Jolla Pharmaceuticals (developing angiotensin II; Dr. Russell chairs the DSMB of a trial of angiotensin II), CytoVale Inc. (developing a sepsis diagnostic), and Asahi Kesai Pharmaceuticals of America (AKPA) (developing recombinant thrombomodulin). Dr. Russell reports having received an investigator-initiated grant from Grifols that is provided to and administered by UBC.

Received: 12 July 2016 Accepted: 14 July 2016

Published online: 30 September 2016

\section{References}

1. Linder A, Fjell C, Levin A, Walley KR, Russell JA, Boyd JH (2014) Small acute increases in serum creatinine are associated with decreased long-term survival in the critically ill. Am J Resp Crit Care Med 189:1075-1081

2. Herridge MS, Tansey CM, Matte A, Tomlinson G, Diaz-Granados N, Cooper A et al (2011) Functional disability 5 years after acute respiratory distress syndrome. N Engl J Med 364:1293-1304

3. Linder A, Guh D, Boyd JH, Walley KR, Anis AH, Russell JA (2014) Long-term (10-year) mortality of younger previously healthy patients with severe sepsis/septic shock is worse than that of patients with nonseptic critical illness and of general population. Crit Care Med 42:2211-2218

4. Cuthbertson BH, Elders A, Hall S, Taylor J, MacLennan G, Mackirdy F, Mackenzie SJ, Scottish Critical Care Trials Group, Scottish Intensive Care Society Audit Group (2013) Mortality and quality of life in the 5 years after severe sepsis. Crit Care 17:R70

5. Linder ALT, Fisher J, Singer J, Boyd J, Walley KR, Russell JA (2016) Short term organ dysfunction is associated with long term (10-year) mortality of septic shock. Crit Care Med (in press)

6. Donnelly JP, Hohmann SF, Wang HE (2015) Unplanned readmissions after hospitalization for severe sepsis at Academic Medical Center-Affiliated Hospitals. Crit Care Med 43:1916-1927

7. Grander W, Dünser MW (2010) Prolonged inflammation following critical illness may impair long-term survival: a hypothesis with potential therapeutic implications. Med Hypotheses 75:32-34

8. Kaynar AM, Yende S, Zhu L, Frederick DR, Chambers R, Burton CL, Carter M, Stolz DB, Agostini B, Gregory AD, Nagarajan S, Shapiro SD, Angus DC (2014) Effects of intra-abdominal sepsis on atherosclerosis in mice. Crit Care 18:469 
9. Yende S, Linde-Zwirble W, Mayr F, Weissfeld LA, Reis S, Angus DC (2014) Risk of cardiovascular events in survivors of severe sepsis. Am J Resp Crit Care Med 189:1065-1074

10. Holst LB, Haase N, Wetterslev J, Wernerman J, Guttormsen AB, Karlsson S et al (2014) Lower versus higher hemoglobin threshold for transfusion in septic shock. N Engl J Med 371:1381-1391

11. Ryegard SL, Holst LB, Wetterslev J, Winkel P, Johansson P, Wernerman J, Guttormsen AB, Karlsson S, Perner A (2016) Long-term outcomes in patients with septic shock transfused at a lower versus a higher haemoglobin threshold: the TRISS randomised, multicentre clinical trial. Intensive Care Med. doi:10.1007/s00134-016-4437-x

12. Holst LB, Haase N, Wetterslev J, Wernerman J, Aneman A, Guttormsen AB, Johansson PI, Karlsson S, Klemenzson G, Winding R, Nebrich L, Albeck C, Vang ML et al (2013) Transfusion requirements in septic shock (TRISS) trial_-comparing the effects and safety of liberal versus restrictive red blood cell transfusion in septic shock patients in the ICU: protocol for a randomised controlled trial. Trials 14:150

13. Bateman A, McArdle F, Walsh T (2009) Time course of anemia during 6 months follow up following intensive care discharge and factors associated with impaired recovery of erythropoiesis. Crit Care Med 37:1906-1912

14. Hebert PC, Wells G, Blajchman MA, Marshall J, Martin C, Pagliarello G, Tweeddale M, Schweitzer I, Yetisir E, Transfusion Requirements in Critical Care Investigators, Canadian Critical Care Trials Group (1999) A multicenter, randomized, controlled clinical trial of transfusion requirements in critical care. N Engl J Med 340:409-417

15. Murphe GJ, Pike K, Rogers CA, Wordsworth S, Stokes EA, Angelini GD, Reeves BC, TITRe2 Investigators (2015) Liberal or restrictive transfusion after cardiac surgery. N Engl J Med 372:997-1008

16. Lilja G, Nielsen N, Friberg H, et al. (2015) Cognitive function in survivors of out-of-hospital cardiac arrest after target temperature management at $33^{\circ} \mathrm{C}$ versus $36^{\circ} \mathrm{C}$. Circulation 131:1340-1349

17. Cronberg T, Lilja G, Horn J (2015) Neurologic function and health-related quality of life in patients following targeted temperature management at $33^{\circ} \mathrm{C}$ vs $36^{\circ} \mathrm{C}$ after out-of-hospital cardiac arrest: a randomized clinical trial. JAMA Neurol 72:634-641
18. Perner A, Haase N, Winkel P, et al. (2014) Long-term outcomes in patients with severe sepsis randomised to resuscitation with hydroxyethyl starch 130/0.42 or Ringer's acetatelntensive Care Med 40:927-934

19. Wittbrodt P, Haase N, Butowska D (2013) Quality of life and pruritus in patients with severe sepsis resuscitated with hydroxyethyl starch longterm follow-up of a randomised trial Crit Care 17:R58

20. Needham DM, Dinglas VD, Morris PE, Jackson JC, Hough CL, MendezTellez PA, Wozniak AW, Colantuoni E, Ely EW, Rice TW, et al.; for the NIH NHLBI ARDS Network (2013a) Physical and cognitive performance of patients with acute lung injury 1 year after trophic versus enteral feeding: EDEN trial follow-up. Am J Respir Crit Care Med 188:567-576

21. Needham DM, Dinglas VD, Bienvenu OJ, Colantuoni E, Wozniak AW, Rice TW, Hopkins RO; NIH NHLBI ARDS Network (2013b) One year outcomes in patients with acute lung injury randomised to initial trophic or full enteral feeding: prospective follow-up of EDEN randomised trial. BMJ 346:f1532

22. Clermont $G$, Kong L, Weissfeld LA (2011) The effect of pulmonary artery catheter use on costs and long-term outcomes of acute lung injury. PLoS One 6:e22512

23. Jackson JC, Girard TD, Gordon SM, Thompson JL, Shintani AK, Thomason JW, Pun BT, Canonico AE, Dunn JG, Bernard GR, Dittus RS, Ely EW (2010) Long-term cognitive and psychological outcomes in the awakening and breathing controlled trial. Am J Respir Crit Care Med 182:183-191

24. Laterre PF, Abraham E, Janes JM, Trazaskoma BL, Correll NL, Booth FV (2007) ADDRESS (Administration of DRotrecogin alfa [activated] in Early stage Severe Sepsis) long-term follow-up: one-year safety and efficacy evaluation. Crit Care Med 35:1457-1463

25. Steinberg KP1, Hudson LD, Goodman RB, Hough CL, Lanken PN, Hyzy R, Thompson BT, Ancukiewicz M; National Heart, Lung, and Blood Institute Acute Respiratory Distress Syndrome (ARDS) Clinical Trials Network (2006) Efficacy and safety of corticosteroids for persistent acute respiratory distress syndrome. N Engl J Med 354:1671-1684

26. Angus DC, Clermont G, Linde-Zwirble WT, Musthafa AA, Dremsizov TT, Lidicker J, Lave JR; NO-06 Investigators (2006) Healthcare costs and longterm outcomes after acute respiratory distress syndrome: a phase III trial of inhaled nitric oxide.Crit Care Med 34:2883-2890 